\title{
AC 2011-2226: TESSAL: PORTABLE DISTRIBUTED LABORATORIES IN THE ECE CURRICULUM
}

\author{
Bonnie Ferri, Georgia Tech
}

Bonnie Ferri received a BS from Electrical Engineering from Notre Dame in 1981, a MS in Mechanical and Aerospace Engineering from Princeton in 1984, and a PhD in Electrical Engineering from Georgia Tech in 1988. She is currently a Professor and Associate Chair for Graduate Affairs in ECE at Georgia Tech. Her research has been in the areas of embedded control systems, applications of control, control of computing systems, and education. She is the recipient of the 2007 IEEE Education Society Harriet B. Rigas Award.

\section{JillL L Auerbach, Georgia Institute of Technology}

Jill Auerbach is a Senior Academic Professional in the School of Electrical and Computer Engineering at Georgia Institute of Technology. As the Coordinator of Assessment and Student Retention in the School, she is responsible for accreditation and program review requirements and assessment of several special academic programs. In addition, Jill directs programs that promote student retention and success, especially among underrepresented, female and transfer student cohort groups. Her educational background is in the fields of Policy Analysis and Public Administration, with emphasis on research methodology.

\section{Jennifer E. Michaels, Georgia Institute of Technology}

Jennifer E. Michaels received the B.E.E. degree from the Georgia Institute of Technology (Georgia Tech), Atlanta, Georgia, in 1976, and the M.S. and Ph.D. degrees in theoretical and applied mechanics from Cornell University, Ithaca, New York, in 1982 and 1984, respectively. She worked as an engineer with the Hanford Engineering Development Laboratory in Richland, Washington, from 1977 to 1980. She was co-founder and vice president of JTM Systems and Consulting, Inc., Ithaca, New York, from 1980 to 1988 , working primarily on the development, fabrication and commissioning of custom automated ultrasonic inspection systems. She continued this work from 1988 until 2002 as Manager of Systems Development at Panametrics, Inc., in Waltham, Massachusetts. In 2002 she joined the faculty of the School of Electrical and Computer Engineering at Georgia Tech where she is an Associate Professor and co-director of the QUEST (Quantitative Ultrasonic Evaluation, Sensing and Testing) Laboratory. Prof. Michaels is a senior member of the IEEE, a member of the Acoustical Society of America and the American Society of Nondestructive Testing, and an Associate Editor of the IEEE Transactions on Instrumentation and Measurement. Her research interests include signal processing, wave propagation, pattern recognition, detection and estimation, data fusion, and automated measurement systems, primarily relating to ultrasonic structural health monitoring and nondestructive evaluation.

\section{Douglas B. Williams, Georgia Institute of Technology}

Douglas B.Williams received the BSEE, MS, and PhD degrees in electrical and computer engineering from Rice University, Houston, Texas. In 1989, he joined the faculty of the School of Electrical and Computer Engineering at the Georgia Institute of Technology, Atlanta, Georgia, where he is currently Professor and Associate Chair for Undergraduate Affairs. There he is also affiliated with the Center for Signal and Image Processing (csip.ece.gatech.edu) and the Teaching Enhancement via Small-Scale Affordable Labs Center (www.ece.gatech.edu/research/tessal/index.html).

Dr. Williams has served as an Associate Editor of the IEEE Transactions on Signal Processing and the EURASIP Journal of Applied Signal Processing. He is currently on the IEEE Signal Processing Society's Education Technical Committee, and he has been a member of the Society's Board of Governors and Signal Processing Theory and Methods Technical Committee. Dr. Williams was co-editor of the Digital Signal Processing Handbook published by CRC Press and IEEE Press. He is a member of the Tau Beta $\mathrm{Pi}$, Eta Kappa $\mathrm{Nu}$, and Phi Beta Kappa honor societies. 


\title{
TESSAL: Portable Distributed Laboratories in the ECE Curriculum
}

\begin{abstract}
:
The TESSAL (Teaching Enhancement via Small-Scale Affordable Labs) Center, funded by an NSF CCLI project, seeks to improve undergraduate learning by developing small-scale, portable experiments for inclusion into a wide selection of Electrical and Computer Engineering (ECE) lecture-based courses. Since these courses currently do not have labs associated with them, these experiments add a hands-on active learning component to the courses. The labs developed as part of this project include ones for digital logic, circuits, signals and systems, control systems, power generation, random processes, and electromagnetics. The labs are described in this paper along with the web support. Best practices and assessment methods are also discussed.
\end{abstract}

\section{Introduction}

Distributed laboratories contain portable experiments that can be done in various locations such as homes, classrooms, and dorm rooms. These labs utilize inexpensive equipment and student resources such as laptops, and do not require the specialized equipment housed in centralized laboratory locations. As such, these experiments are well-suited for inclusion into lecture-based classes to be done at the desks in the class room or to be taken home as a project. These types of experiments allow for a new pedagogical model that promotes a more complete integration of theory and laboratory experience within the format of a standard lecture-based course [1].

Small affordable devices for labs are used at a number of institutions [1-10], and are sometimes called "lab-in-a-box" or "lab-at-home" [2,6,7]. Oliver [2] and Zhu [3] promote the use of programmable logic devices in introductory digital logic courses. These devices cost on the order of $\$ 100$ and can be purchased by students for use during the term or provided on loan from the university for the semester. Both Oliver [2] and Zhu [3] report that grades on the final exams increased during terms in which the laboratories were used. The CricketSat circuit $(\sim \$ 10)$ is mentioned for use in a freshman design course [4]. Another recent platform is the National Instruments myDAQ, a student data acquisition board [10,12]. This board is priced for student purchase (\$175) and can be used in a variety of courses to take measurements of voltages and currents. The TESSAL Center uses myDAQs in several of its lab modules.

Holbert [11] studied active learning methods within a computer-equipped classroom and found that laboratory experience ranked among students in a electric circuits course as having the third highest impact on their learning (behind homework and in-class examples, and in front of lectures, exams, powerpoint slides and the textbook). However, the efforts reported in [2-10] generally are done on a small scale, uncoordinated between courses and often without extensive web-based support. Despite these limitations, these papers do demonstrate the feasibility and usefulness of hands-on experiments to supplement lecture courses as are presented in this paper.

The TESSAL Center was established to provide a coordinated and cross-curriculum approach to the inclusion of small scale-labs into lecture-based courses. The initial paper on this topic [1] presented the concept underlying TESSAL, the preliminary development of five labs, and the outline for web development. Details of specific labs are highlighted in [8] and [9]. This paper presents more labs along with a discussion of the web components [13], best practices, 
assessment, and how distributed labs fit into a curriculum (rather than just specific courses as outlined in [2-10]).

\section{Description of the TESSAL Laboratory Modules}

The TESSAL Center has 13 modules in the areas of digital logic, circuits, electromagnetics, signals and systems, control systems, power generation, and random processes. Most of the experiments are low cost and portable, which facilitates a decentralized laboratory environment where students perform the experiments at their homes or in the classroom while at their desks, rather than in dedicated laboratories. These labs were designed with the following objectives and features.

To maximize the benefits of incorporating experiments into a lecture course, the laboratory module should not only excite students about the material, it should fully support or demonstrate a fundamental principle that is hard to understand from theory alone. The concepts demonstrated in the lab should appear in standard course evaluation methods such as in-class exams. One way to satisfy these needs is for the laboratory modules to contain supplemental material including a tutorial for students on the fundamental concepts being taught and an online quiz for them that gives representative questions on the material that might be found on a standard exam.

To maximize the wide-spread usage of distributed laboratory modules, certain logistical considerations must be met. Essentially, each experimental module should be made as accessible as possible to as wide a range of instructors as possible. These experimental modules should be designed primarily for faculty who neither have resources for high-end experiments nor want to spend a lot of time developing, building or maintaining experiments. They should not be fragile, and they should be portable. Furthermore, the hands-on demos and experiments must be easy for students to use without the need for a lengthy learning period.

Table 1, taken from the supporting website, shows the available labs and the concepts that they address. 


\section{TABLE 1: TESSAL Laboratory Modules}

\section{Digital Logic}

\begin{tabular}{|c||c|c|}
\hline \multicolumn{2}{|c|}{ Labs } & \multicolumn{1}{|c|}{ Concepts } \\
\hline Finite State Machine & Goals \&Description \\
\hline Design of combinational circuits & $\begin{array}{c}\text { The goal of this experiment is to reinforce } \\
\text { state machine concepts by having students } \\
\text { design and implement a state machine } \\
\text { using a decoder, State transition simple chips and a protoboard. This } \\
\text { experiment also introduces students to } \\
\text { table and diagram, Pin diagrams }\end{array}$ \\
\hline
\end{tabular}

\section{RC Circuits}

\begin{tabular}{|c|c|c|}
\hline Labs & Concepts & Goals \&Description \\
\hline$\frac{\text { Resistive and RC Circui }}{\text { R }}$ & $\begin{array}{l}\text { Resistive networks, first and } \\
\text { second-order circuits, step } \\
\text { response, time constant }\end{array}$ & $\begin{array}{c}\text { The goal is to introduce physical RC } \\
\text { components and explore how they behave } \\
\text { in circuits. Students use myDAQ boards } \\
\text { connected to their laptops. }\end{array}$ \\
\hline Frequency Response & $\begin{array}{l}\text { Frequency response, } \\
\text { resonance, filtering }\end{array}$ & $\begin{array}{l}\text { Students explore steady-state sinusoidal } \\
\text { responses of first and second-order circuits } \\
\text { at difference frequencies. They take } \\
\text { measurements to plot the Bode Plot using } \\
\text { myDAQ boards. }\end{array}$ \\
\hline
\end{tabular}

\section{Signals and Systems}

\begin{tabular}{|c|c|c|}
\hline Labs & Concepts & Goals \&Description \\
\hline Light Sensor & $\begin{array}{c}\text { Aliasing, Frequency Analysis, } \\
\text { Digital Filtering }\end{array}$ & $\begin{array}{l}\text { Data is recorded by one or two light } \\
\text { sensors while the light in the room is turned } \\
\text { on and off. The students are asked to } \\
\text { design and implement a lowpass filter to } \\
\text { remove noise. The source of the noise is } \\
\text { investigated }\end{array}$ \\
\hline Shaded Disk & $\begin{array}{c}\text { Periodic Signals, Chirp Signals, } \\
\text { Aliasing, Highpass and Lowpass } \\
\text { Filters }\end{array}$ & $\begin{array}{l}\text { A motor turns the disk resulting in a } \\
\text { sinusoidal signal measured from the light } \\
\text { sensor. Students are asked to design and } \\
\text { implement various types of filters. }\end{array}$ \\
\hline
\end{tabular}




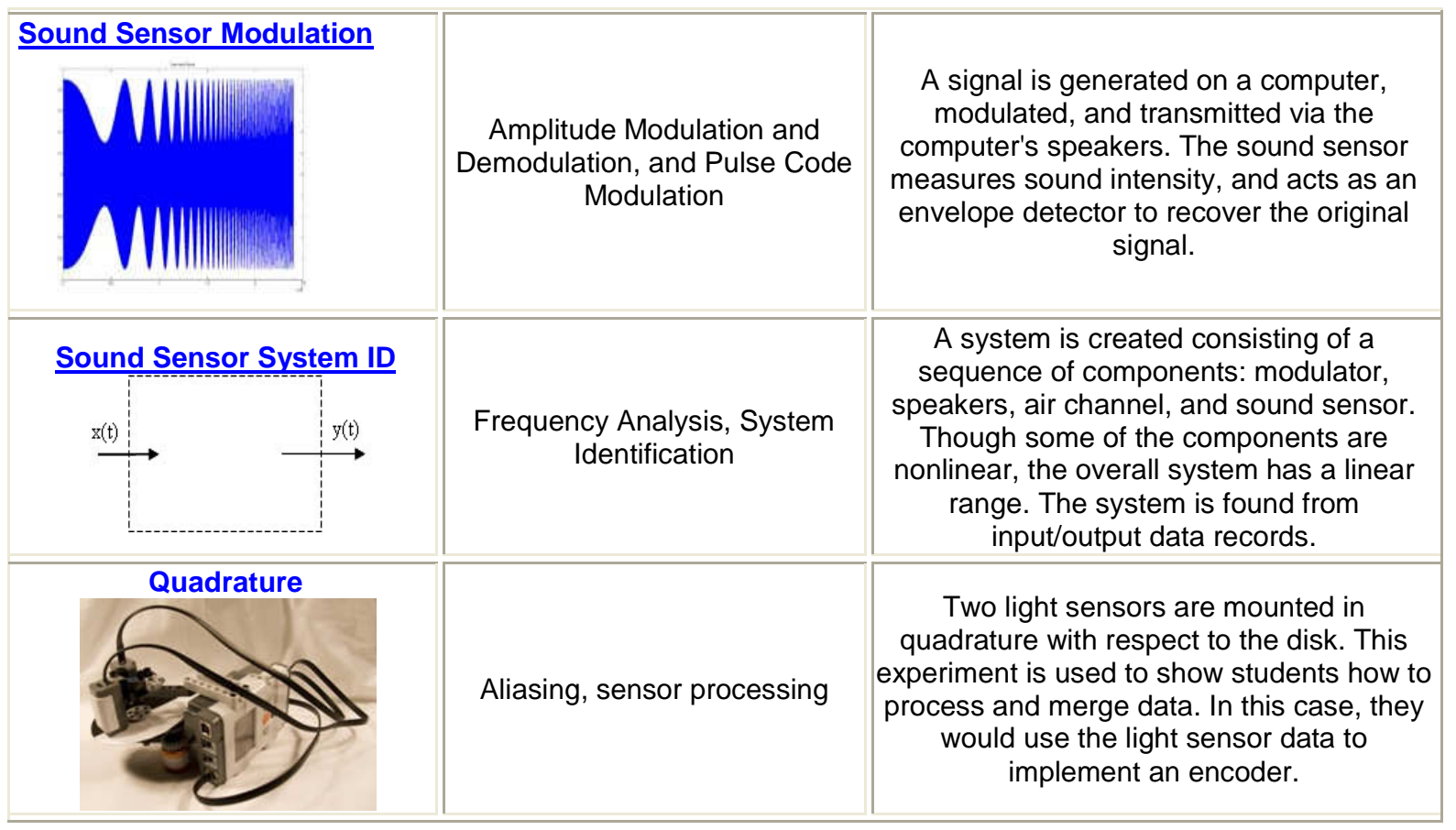

\section{Control Systems}

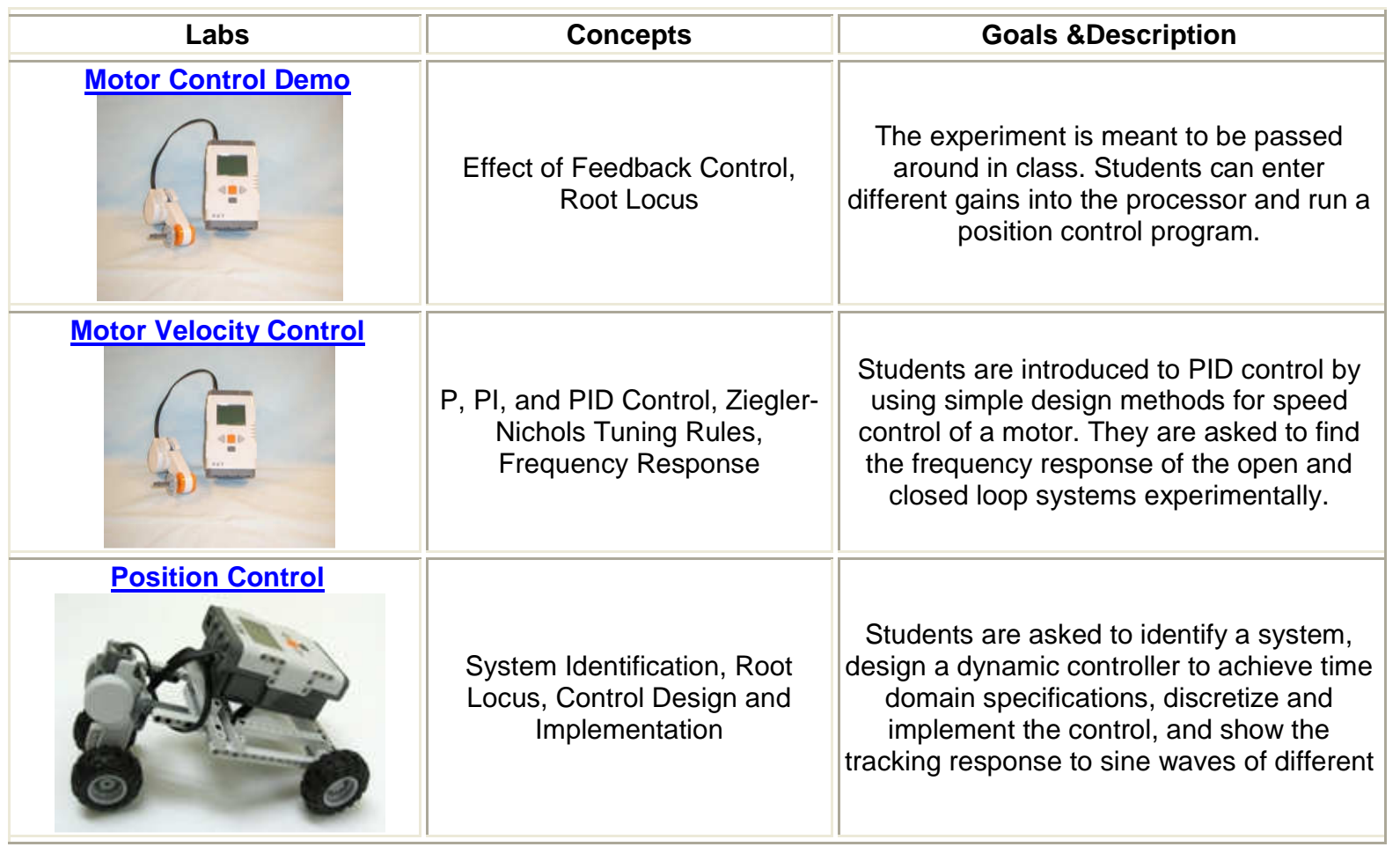




\section{Electric Energy}

\begin{tabular}{|c|c|c|}
\hline Labs & Concepts & Goals \&Description \\
\hline$\underline{\text { Solar Energy }}$ & $\begin{array}{l}\text { Current-voltage curves, } \\
\text { Maximum power point, } \\
\text { Dependence on angle if } \\
\text { incidence and distance }\end{array}$ & $\begin{array}{l}\text { Performed in class, this experiment } \\
\text { demonstrates the current-voltage-power } \\
\text { relationships in solar generation. .Students use } \\
\text { a solar panel and equipment to record voltage } \\
\text { and current. The experiment can be performed } \\
\text { using a portable DVM or using a signal } \\
\text { measurement device and the student's laptop. }\end{array}$ \\
\hline & $\begin{array}{l}\text { Power generation, efficiency, } \\
\text { effect of load (LED and } \\
\text { incandescent bulbs) }\end{array}$ & $\begin{array}{l}\text { A generator, a small DC motor, is hooked up to } \\
\text { two possible loads: an LED bulb and an } \\
\text { incandescent bulb. Students learn about } \\
\text { efficiency as they turn the generator shaft and } \\
\text { feel the large difference in effort between } \\
\text { powering an incandescent and an LED bulb. } \\
\text { With the myDAQ, the current and voltage } \\
\text { waveforms for each load can be viewed and } \\
\text { analyzed. }\end{array}$ \\
\hline
\end{tabular}

\section{Electromagnetics}

\begin{tabular}{|c|c|c|}
\hline Labs & Concepts & Goals \&Description \\
\hline$\frac{\text { Radio Frequency }}{\underline{\text { Identification }}}$ & $\begin{array}{l}\text { Basic electromagnetic } \\
\text { principles, RF principles, } \\
\text { Induction and magnetism }\end{array}$ & $\begin{array}{l}\text { This lab shows students the effects of } \\
\text { electromagnetic principles on RFID } \\
\text { equipment. Students use an antenna, RF } \\
\text { tag, RFID reader, their own laptop, and a } \\
\text { ruler. Students examine the sensitivity of } \\
\text { the range and orientation of the RF tag to } \\
\text { the antenna. They also examine the effects } \\
\text { of measurements through a dielectric field } \\
\text { (obtained by reading the tag through the } \\
\text { desk). }\end{array}$ \\
\hline
\end{tabular}

Each of the modules in Table 1 links to supporting material on the TESSAL website. The supporting web resources include:

- Tutorial on fundamental, theoretical concepts demonstrated in the lab

- Instructional videos for how to run the labs

- Laboratory procedures for students to follow to do the lab

- Online problems representative of those found in lecture-based course exams

- Instructor resources for building the platform and for implementing it

These resources satisfy two goals for the center: 1) to maximize the benefits of incorporating the experiments into the course and 2) to maximize wide-spread usage of the experiments. The website material ties the experiments to lecture material as well as provides support for students and instructors. Student support is aimed at tying the experimental material closely to the fundamental concepts taught in lectures and at streamlining the experimental procedures so that there is not a large learning curve. The instructor support materials are built to encourage a target group, those faculty who normally teach lecture courses rather than labs, to adopt the experiments by making it simple to use and easy to incorporate into classes. 
These modules have been used in 10 different courses. Over 1600 students have participated in the TESSAL Center laboratory activities, and 21 different instructors have been involved. Through this experience, a list of best practices has emerged for the logistics of implementing the experiments.

A working list of best practices for out-of-class experiments includes:

- Assignment must be mandatory and thus on the course syllabus to ensure compliance.

- Use a reservation system for students to reserve modules ahead of time.

- Penalize groups 5\% for each instance of tardiness (more than $1 / 2$ hour late).

- Put the modules in small, sturdy boxes; tackle boxes or tool boxes work well to protect modules that might otherwise get damaged if put into a book bag.

- Have a place where students can come to work on the lab during TA office hours so that they can ask questions.

A working list of best practices for in-class experiments includes:

- Test all experimental modules before class.

- Ensure adequate time in class for both instruction and implementation phases. The experiment should not be seen as an add-on.

- Strongly encourage all students to come prepared for the lab (or risk not completing it). Preparation includes completing prelab assignments, reading the fundamental concepts tutorial, printing the lab instructions for class, and viewing the instructional video.

- Have the instructional video available on the instructor's laptop for students who need to review it during the lecture.

- Limit the number of TA check points in the labs to a level that can be completed by the available number of TAs during the allotted class period.

\section{Results and Assessment:}

The process of incorporating active learning opportunities in lecture-based courses presents challenges for instructors who must make the modifications to the course to accommodate these enhancements. Since a primary goal of TESSAL is to realize the widespread use of portable laboratories throughout the curriculum, the assessment model must also focus how to best support this goal. Using both quantitative and qualitative data to understand and evaluate the utility of the broad-based inclusion of portable laboratories, three research questions were identified that will contribute to our understanding:

1. Will student interest and response to course topics be more favorable in lecture classes that integrate hands-on learning opportunities?

2. Will student achievement on course-related assignments improve in lecture classes that integrate hands-on learning opportunities?

3. What strategies can be used to provide a low cost, portable means of introducing experiments in lecture courses?

Since the implementation of TESSAL is an incremental process, answers to these research questions comes incrementally. Throughout the project, several assessment tools have been used and include pre- and end-of-course surveys, a quasi-experimental design concept inventory testing, post-course surveys (taken a semester later), monitoring student performance on related assignments/tests, and observation. The next section provides examples of findings thus far, 
primarily addressing the first research question and implications for developing efficient strategies for implementation.

\section{Findings}

One of the lecture-based courses that was targeted early-on for portable laboratories (State Machine Module) was Introduction to Computer Engineering. This is a required course for both Computer Engineering and Electrical Engineering majors, and a technical elective for Industrial and Systems Engineering majors. The make-up of any particular class is a mix of these majors. Data has been collected from eleven sections of this course over four semesters. Six of those sections include three control and three experimental sections.

The assessment of using the State Machine Module consists of two parts: reviewing performance assignments/tests on those questions that correspond to the material covered by the experiment and conducting student surveys about their interest and understanding of the material. Survey data show that students in the experimental classes have a better understanding of the state machine material than in the traditional lecture-only classes. For six classes (three pairs of experimental and control classes and each pair taught by the same instructor), higher percentages of students in each of the control classes report that they did not understand the state machine material as well as other material in the class. These data are presented in Table 1. Each pair refers to one control class (no portable lab) and one experimental class with a portable lab component. Each pair was taught by the same faculty instructor.

\begin{tabular}{|l|c|c|}
\hline \multicolumn{3}{|c|}{$\begin{array}{c}\text { Table 2 } \\
\text { Percentage of student reporting that their understanding of } \\
\text { protoboards/breadboard was not as good as other topics in the course }\end{array}$} \\
\hline & Control & Experimental \\
\hline Pair \#1 Spring semester 2008 & $82.8 \%$ & $5.7 \%$ \\
\hline Pair \#2 Fall semester 2008 & $74.3 \%$ & $47.6 \%$ \\
\hline Pair \#3 Fall semester 2009 & $66.7 \%$ & $31.9 \%$ \\
\hline
\end{tabular}

Several observations can be made about the data in Table 2. A survey was conducted at the beginning of the semester in each class and students were asked a series of questions about their knowledge and experience in specific topic areas. One of the questions asked if students had experience working with protoboards before taking the class. There were only a handful of students who reported any experience, and there is no evidence that the experimental classes had more students with that experience. Another interesting point is that the same instructor taught the spring and fall 2008 sections, and it was the first semester using the portable laboratory experiment that the highest percentage of students reported the better understanding of the material covered by the lab. One difference among the experimental sections is completion of the pre-lab state machine homework assignments. For the spring 2008 students, only one student did not complete the homework and only one student of 39 reported that there was inadequate inclass preparation for the lab. In fall 2008, 9 students out of 24 did not complete the pre-lab assignment. Not only were students not as conscientious about the pre-lab assignment, but close to half reported that they needed more preparation. Of all 6 sections, this one had the most comments that pertained to the need for more time, better preparation and more instructions. 
Survey data from the other sections of Introduction to Computer Engineering support the need to complete the pre-lab assignments and to manage efficiently the execution of the experiment. In another section with a different instructor who did only the experimental class, 7 of 28 students did not do the pre-lab assignment and $40 \%$ of the students reported they did not understand protoboards as well as the other material. In a different section taught by another instructor who reported that the pre-lab video did not work and the instructor did not attend class, $42 \%$ of students did not understand protoboards as well as other material. However, several of the comments stated that students wanted to see more in-class experiments. In analyzing survey data for the 8 sections that had the portable lab component, the data suggest that the classes where the experiment was managed efficiently and students completed the pre-lab homework were more successful in terms of understanding the complex topic and concepts covered by the lab.

One additional noteworthy finding from the survey data is the enthusiasm expressed by students in a section of the course where several supplements to the experiment were available. In this section of Introduction to Computer Engineering, the instructor had not only a pre-lab homework assignment and on-line video-tutorial, but additional on-line supplements. While $30 \%$ of the students reported less understanding of protoboards that other topics, all of the students reported adequate preparation for the laboratory and 8 of 13 suggestions were to have more experiments like that one. Since this class had 6 associated supplements, additional analysis will be needed to determine if any supplements are more effective than others in helping students understand protoboards.

In a junior level- course, Systems and Controls, data has been collected from six sections of the course. Among the six is one pair of a control class and an experimental class, both taught by the same instructor. The portable lab experiments that were used were the light sensor project and the motor velocity position and control project. Several observations can be made. While the students in the experimental section reported higher levels of understanding the material covered by the experiments compared to the control class, follow-up surveys administered one semester later support the lasting impact of using the experiments. From the control class, $21 \%$ of students took another Systems and Controls class and 33\% did so from the experimental class. More compelling however is that only $29 \%$ of students from the control class said that their interest in applications of control engineering had increased since taking the course, yet $62 \%$ from the experimental class reported this gain.

On this same survey administered one semester after the Systems and Controls class was completed, students were given a list of nine topics that were covered in the class and were asked to rate their current level of understanding of each topic. These findings are presented in Table 3 below.

In the experimental class, portable labs were integrated into the course that covered 9 of the topics listed in Table 3. For several of the topics, the percentages of "solid understanding" students are relatively close for each of the two classes. On other topics, such as root locus methods, discretization of continuous-time systems, discrete time control systems and to a lesser extent implementation of digital filters, the percentage of students reporting "solid understanding" is considerably higher. This pattern is reversed for one of the two topics, Nyquist stability criterion, that was not addressed by the portable labs used in the experimental class. This is noteworthy for two reasons. First, one argument against the integration of experiments in lecture classes is that it can be too time-consuming and can dilute coverage of other topics. Second, since the differences for several of the topics are so large in terms of the 
percentage of students indicating "solid understanding" from the experimental class, this data may suggest that active learning may increase the likelihood that students will retain the information.

\begin{tabular}{|c|c|c|}
\hline \multicolumn{3}{|c|}{$\begin{array}{c}\text { Table } 3 \\
\text { Follow-Up Survey for System and Controls Students from Previous Semester } \\
\text { Percentage of Students That Rated "Solid Understanding" for } 11 \text { Topics Covered in the } \\
\text { Course }\end{array}$} \\
\hline & Control & Experimental \\
\hline Implementation of digital filters & $29 \%$ & $48 \%$ \\
\hline Transient response of 1 st and 2 nd order systems & 71 & 67 \\
\hline Steady state response of systems & 71 & 71 \\
\hline Root locus methods & 36 & 52 \\
\hline Frequency response methods & 43 & 48 \\
\hline Routh-Hurwitz stability criterion* & 36 & 38 \\
\hline Nyquist stability criterion* & 36 & 10 \\
\hline PID controllers & 29 & 43 \\
\hline Lead and lag controllers & 36 & 38 \\
\hline Discretization of continuous-time systems & 14 & 62 \\
\hline Discrete time control systems & 14 & 43 \\
\hline
\end{tabular}

*Topics not covered by portable lab experiments

The findings from both Introduction to Computer Engineering and Systems and Controls courses demonstrate that student interest increases in the classes that utilize the portable labs. Survey data shows that students respond more favorably to the course material and are more likely to report better understanding of material covered by the experiments as compared with the traditional lecture. Further analysis of the implementation of the experiments reveals that supplemental materials and efficiency have an impact on student response to the experiments, which confirms the need to develop a set of "best practices" to achieve widespread integration of portable labs in lecture-based courses.

\section{Integration Across the Curriculum}

The major revisions to our curriculum that are now in progress offer several opportunities for a more thorough integration of the hands-on modules being developed in this program. Almost all required courses are undergoing at least minor changes, and new courses are being created. These changes provide a chance to design modules that build on related materials used in earlier, prerequisite classes. As an example, we are planning to use the National Instruments myDAQ in our sophomore-level circuits course. Its use is currently optional, left up to the instructor, but we are considering making its use mandatory. The myDAQ integrates with a personal computer to 
provide a low cost platform for data acquisition, circuit analysis, and system prototyping. The flexibility of the myDAQ and its associated tools allows its incorporation into a variety of courses at different levels within the program.

The sophomore-level circuits course is a traditionally structured course covering time domain and frequency domain circuit analysis. This course does not have a lab component, although students do take a required lab in a later semester. Modules under development for this course that use the myDAQ include ones that examine the variability of real circuit elements, the time and frequency domain responses of RC circuits, and simple op amp circuits.

Later junior-level required courses include signals and systems, microelectronics, and electromagnetics. All of these courses are good candidates for the development of hands-on modules, as none of them include an integrated lab. Students taking these courses will have taken the prerequisite circuits course, so the modules for these courses can build on the earlier circuits modules. Working from the multi-domain analysis learned in the circuits' modules, materials will be developed for the signals and systems course for the evaluation of simple filters. The microelectronics courses covers circuits that include transistors, diodes, and op amps - all of which are suitable for exercises based on the myDAQ

Under the revised curriculum, many senior level elective courses will be offered with these junior level courses as prerequisites. Most of these elective courses will be lecture-only and provide no integrated lab experience. However, students who have taken the earlier courses will already have myDAQs and will be familiar with their use. One measure of success for this program will be when faculty begin to develop and use myDAQ experiments and hands on assignments in these elective classes.

\section{Program Evaluation}

As described earlier in this paper, the evaluation of the materials developed in this project have to date focused on the effectiveness of individual modules within each course. Future assessment will include an examination of the effectiveness of the program as a whole.

Our ongoing ABET Program Outcomes assessment provides an opportunity for evaluating this program in the context of the basic skills that students are expected to master. ABET's Criterion 3 (Program Outcomes) requires that programs demonstrate student attainment of 11 outcomes, designated (a) through (k). Of these outcomes, the most directly relevant is Outcome (b): an ability to design and conduct experiments, as well as to analyze and interpret data. Outcomes (a) and (k) are also relevant to this project, though to a lesser degree. Outcome (a) is an ability to apply knowledge of mathematics, science, and engineering and Outcome $(\mathrm{k})$ is an ability to use the techniques, skills, and modern engineering tools necessary for engineering practice.

When assessing these outcomes, the cohort of students that has taken those courses that have used this project's modules will be evaluated separately. By comparing the achievements of these students against the remainder of our undergraduates, we will be capable of weighing the benefits and costs of the integration of these modules throughout the curriculum. Initially, many of these students will have taken only a subset of the courses using the modules, and some indication of the effectiveness in individual courses may be assessed.

For some courses, instructors will have the option of whether or not to use the modules in their sections. Thus, other metrics for the evaluation of this program can examine the depth of use of 
these tools within the curriculum. Among the metrics to be used is the number of courses for which modules have been developed and, for multi-section courses, the percentage of sections using the modules each term. Ultimately, we can also determine the percentage of our graduates who have had access to this project's materials and the number of courses where they have used them.

In evaluating the use of these small-scale experiments in multi-section courses, we will also survey the faculty to determine why they did or did not use the experiments. The goals of these surveys would be to identify both the advantages of the experiments and the barriers, both actual and perceived, to their adoption.

\section{Acknowledgement}

Sponsor: NSF CCLI Program, Russell Pimmel Project Director, project number 0618645. The authors appreciate the help of Edgar Jones, James Steinberg, Greg Durgin, Miroslav Begovic, Hongyi Qu, Greg Droge, and Safayet Ahmed in building the experimental platforms.

\section{References}

[1] B. Ferri, J. Auerbach, J. Jackson, J.E. Michaels, D. Williams, “A Program For Distributed Laboratories In The ECE Curriculum” ASEE Annual Conference and Exposition, Pittsburgh, June 2008.

[2] J. Oliver and F. Haim, "Lab at Home: Hardware Kits for a Digital Design Lab," 46 IEEE Transactions on Education, VOL. 52, NO. 1, Feb. 2009, p 46-51

[3] Y. Zhu,T. Weng, and C-K Cheng, "Enhancing Learning Effectiveness in Digital Design Courses Through the Use of Programmable Logic Boards," IEEE Transactions on Education, VOL. 52, NO. 1, Feb 2009151.

[4] J. Frolik and M. Fortney, "A Low-Cost Wireless Platform for First-Year Interdisciplinary Projects," IEEE Transactions On Education, VOL. 49, NO. 1, Feb 2006105.

[5] R. Dua, J.E. Seiffertt, B. Blaha, K. Gupta, V. Satagopan, J.R. Stanley, D. Beetner, and D.C. Wunsch, 2005, "Hands-On Projects and Exercises to Strengthen Understanding of Basic Computer Engineering Concepts," Proceedings of the American Society of Engineering Education Annual Conference \& Exposition, Portland, OR.

[6] W. Durfee, P. Li, and D. Waletzko, 2005, "At-Home System and Controls Laboratories," Proceedings of the American Society of Engineering Education Annual Conference \& Exposition, Portland, OR.

[7] R.W. Hendricks, K.M. Lai, and J.B. Webb, 2005, "Lab-in-a-Box: Experiments in Electronic Circuits That Support Introductory Courses for Electrical and Computer Engineers," Proceedings of the American Society of Engineering Education Annual Conference \& Exposition, Portland, OR.

[8] B. Ferri, S. Ahmed, J. Michaels, E.Dean, C. Garvet, S. Shearman, , "Signal Processing Experiments Wit LEGO MINSTORMS NXT Kit for Use in Signals and Systems Courses," Proceedings of the American Control Conference, St. Louis, pp. 3787-3792., June 2009.

[9] B. Ferri, J. Auerbach, H. Qu, "Distributed Laboratories: A Finite State Machine Module," proceedings of the World Congress In Computer Science, Computer Engineering and Applied Computing, International Conference: Frontiers in Education Conference on Computer Science and Computer Engineering, Las Vegas, NV, July 2010. 
[10] Jianchu Yao; L. Limberis, S. Warren, "Work in progress - A ubiquitous laboratory model to enhance learning in electronics courses offered by two universities with dissimilar curricula ", Proceedings of the IEEE Frontiers in Education Conference, Washington, DC, October 2010. pages: F3C-1 - T1A-2

[11] K. Holbert and G. Karady, "Strategies, Challenges and Prospects for Active Learning in the Computer-Based Classroom", IEEE Transactions On Education, VOL. 52, NO. 1, Feb 200931.

[12] National Instruments myDAQ product page, http://www.ni.com/mydaq/

[13] TESSAL Website : www.ece.gatech.edu/research/tessal/index.html 